\title{
Corrigendum: Inhibition of VEGFR2 Activation and Its Downstream Signaling to ERK1/2 and Calcium by Thrombospondin-1 (TSP1): In silico Investigation
}

\begin{abstract}
Hojjat Bazzazi ${ }^{1 *}$, Jeffrey S. Isenberg ${ }^{2}$ and Aleksander S. Popel ${ }^{1}$
${ }^{1}$ Department of Biomedical Engineering, School of Medicine, Johns Hopkins University, Baltimore, MD, USA, ${ }^{2}$ Division of Pulmonary, Allergy, and Critical Care Medicine, Department of Medicine, Heart, Lung, Blood, and Vascular Medicine Institute, University of Pittsburgh, Pittsburgh, PA, USA
\end{abstract}

Keywords: TSP1, CD47, VEGF, VEGFR2, computational modeling, calcium, ERK1/2

\section{A corrigendum on}

Inhibition of VEGFR2 Activation and Its Downstream Signaling to ERK1/2 and Calcium by Thrombospondin-1 (TSP1): In silico Investigation

by Bazzazi, H., Isenberg, J. S., and Popel, A. S. (2017). Front. Physiol. 8:48. doi: 10.3389/fphys.2017. 00048

In the original article, there was a mistake in the legend for Figure 3 as published.

\section{OPEN ACCESS}

Edited and reviewed by: Shayn Peirce-Cottler,

University of Virginia, USA

*Correspondence: Hojjat Bazzazi

hbazzazi@jhmi.edu

Specialty section:

This article was submitted to

Computational Physiology and

Medicine,

a section of the journal

Frontiers in Physiology

Received: 09 February 2017 Accepted: 24 February 2017

Published: 07 March 2017

Citation:

Bazzazi H, Isenberg JS and Popel AS

(2017) Corrigendum: Inhibition of

VEGFR2 Activation and Its

Downstream Signaling to ERK 1/2 and

Calcium by Thrombospondin-1

(TSP1): In silico Investigation.

Front. Physiol. 8:147.

doi: 10.3389/fphys.2017.00147
"TSP1 inhibition of VEGFR2 signaling with enhanced VEGFR2 degradation. Two nanometer TSP1 is added for $10 \mathrm{~min}$ followed by $40 \mathrm{~min}$ of $50 \mathrm{ng} / \mathrm{ml}$ VEGF...” The correct legend appears below. The authors apologize for this error and state that this does not change the scientific conclusions of the article in any way.

"TSP1 inhibition of VEGFR2 signaling with enhanced VEGFR2 degradation. 2 nM TSP1 is added for $10 \mathrm{~min}$ followed by $40 \mathrm{~min}$ of $50 \mathrm{ng} / \mathrm{ml}$ VEGF..."

Incorrect Author Name

An author name was incorrectly spelled as Jeffery S. Isenberg. The correct spelling is Jeffrey S. Isenberg. The authors apologize for this error and state that this does not change the scientific conclusions of the article in any way.

\section{Text Correction}

In the original article, there was an error on the Introduction section page 2, paragraph 3:

"...we set out here to interrogate potential mechanisms for the inhibition of VEGF/VEGFR2 signaling to ERK1/2 and calcium by TSP1/CD4 interaction utilizing a detailed rule-based model of VEGF signaling to ERK1/2 and calcium...”

A correction has been made to Introduction, paragraph 3:

"...we set out here to interrogate potential mechanisms for the inhibition of VEGF/VEGFR2 signaling to ERK1/2 and calcium by TSP1/CD47 interaction utilizing a detailed rule-based model of VEGF signaling to ERK1/2 and calcium..."

The authors apologize for this error and state that this does not change the scientific conclusions of the article in any way.

In the original article, there was an error on the Conflict of Interest Statement:

"JI serves as chair of the scientific advisory boards of Radiation Control Technologies, Inc. (Jersey City, NJ) and has equity interest in the same and in Tioma Therapeutics (St. Louis, MO)."

A correction has been made to Conflict of Interest Statement: 
"JI serves as chair of the scientific advisory board of Radiation Control Technologies, Inc. (Jersey City, NJ) and has equity interest in the same and in Tioma Therapeutics (St. Louis, MO)."

The authors apologize for this error and state that this does not change the scientific conclusions of the article in any way.

Conflict of Interest Statement: JI serves as chair of the scientific advisory board of Radiation Control Technologies, Inc. (Jersey City, NJ) and has equity interest in the same and in Tioma Therapeutics (St. Louis, MO).
The other authors declare that the research was conducted in the absence of any commercial or financial relationships that could be construed as a potential conflict of interest.

Copyright (C) 2017 Bazzazi, Isenberg and Popel. This is an open-access article distributed under the terms of the Creative Commons Attribution License (CC BY). The use, distribution or reproduction in other forums is permitted, provided the original author(s) or licensor are credited and that the original publication in this journal is cited, in accordance with accepted academic practice. No use, distribution or reproduction is permitted which does not comply with these terms. 